\title{
Balancing the Benefits and Risks: Lessons Learned from the Therapeutic Interventions of a Case with Severe Preeclampsia
}

\author{
Shiqin Xu ${ }^{1}$, Xiaofeng Shen ${ }^{1}$, Fuzhou Wang* ${ }^{1,2}$
}

1. Department of Anesthesiology and Critical Care Medicine, the Affiliated Nanjing Maternity and Child Health Care Hospital, Nanjing Medical University, Nanjing, Jiangsu, China

2. Bonoi Academy of Science and Education, Winston-Salem, USA

Received from Nanjing Medical University, Nanjing, Jiangsu, China.

Submitted on April 23, 2012. Approved on May 28, 2012.

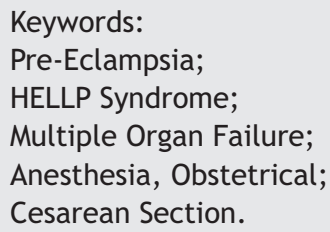

\begin{abstract}
Background and objective: Preeclampsia is a multiple organ dysfunction syndrome (MODS) for its typical and atypical manifestations including hypertension, proteinuria, HELLP syndrome, hypertensive encephalopathy and coagulopathy. Optimal management for such patients is determined from an assessment of the balance between benefits and risks of anesthetic and obstetric therapeutic strategies.

Case Report: A 35-year-old pregnant woman, with one past uncomplicated pregnancy presented at 29 weeks to our medical institute as an emergency with dizziness, chest distress, palpitation, blurred vision and vaginal bleeding. After physical examination and laboratory tests, the patient was diagnosed with severe preeclampsia, HELLP syndrome, placental abruption, and MODS. The patient also presented spinal and pelvic deformity, fixation of articulus mandibularis, and tracheal displacement because of a traffic accident 11 years ago. Therefore, urgent cesarean section was performed under general anesthesia with nasal tracheal intubation using a guide wire. The patient was discharged directly home from the obstetric intensive care unit on the $7^{\text {th }}$ postoperative day with normal blood pressure and full recovery of organic function.

Conclusions: This case merits further discussion on the anesthesia considerations concerning how to make a clinical decision when treating such a patient. Neuraxial block is the first choice for preeclampsia patients undergoing cesarean section when a moderate but not progressive thrombocytopenia exists. When general anesthesia is decided, adequate sedation and analgesia is needed to better control the stress response to intubation especially in patients with neurological signs, and to prevent major cerebral complications.

๑ 2013 Sociedade Brasileira de Anestesiologia. Published by Elsevier Editora Ltda. All rights reserved.
\end{abstract}

*Corresponding author: Department of Anesthesiology and Critical Care Medicine, the Affiliated Nanjing Maternity and Child Health Care Hospital, Nanjing Medical University, No. 123, Tianfei Xiang, Mochou Road, Nanjing 210004, China.

E-mail: zfwang50@njmu.edu.cn

ISSN/\$ - see front metter c 2013 Sociedade Brasileira de Anestesiologia. Published by Elsevier Editora Ltda. All rights reserved. 


\section{Introduction}

Preeclampsia is defined as a multiple organ dysfunction syndrome (MODS) with typical (hypertension and proteinuria) and/or untypical clinical manifestations such as HELLP syndrome (hemolysis, elevated liver enzymes and low platelets), hypertensive encephalopathy and coagulopathy ${ }^{1-3}$. Spinal anesthesia is the first choice for preeclamptic patients for being performed with greater ease and less trauma than the epidural. Although accidental spinal hematoma is a potential risk for these patients ${ }^{4}$, it is still recommended for those with moderate but not progressive thrombocytopenia ${ }^{5-7}$. Successful performance of general anesthesia with remifentanil in these patients was reported ${ }^{8}$, while special attention is needed because a potential risk of difficult airway would be encountered during anesthesia induction from the relatively narrowed oral space in pregnant women that results from fibroelastic edema ${ }^{9}$. Successful anesthesia depends on balancing the benefits and risks for choosing the anesthesia technique and performing obstetric therapeutic strategies.

We hereby report a case of successful management of multipara presenting with preeclampsia, HELLP syndrome, spinal deformity, airway displacement, and limited motion of articulus mandibularis for cesarean section under general anesthesia with a nasal tracheal tube. We learned critical lessons from the nonstandard treatment of the patient, with the exception of how she was managed. With the purpose of improving future clinical care and learning, we reviewed the literature of anesthesia consideration for such patients.

\section{Case Presentation}

We obtained informed consent from the patient before presenting her information and photos for publication.

A 35-year-old pregnant woman at 29 weeks (height, $152 \mathrm{~cm}$; weight, $60 \mathrm{~kg}$ ) with one past uncomplicated pregnancy delivered under cesarean section presented herself at our medical institute with complaints of dizziness, dyspnea, palpitation, blurred vision and vaginal bleeding. At the emergency unit, the patient had a flattened affect and reduced level of consciousness with the Glasgow Coma Score of 11. Physical examination was performed after psychological comfort and found as follows: limited movement of articulus mandibularis leading to only about $0.5 \mathrm{~cm}$ of the oral opening (Figure $1 \mathrm{~A})$, restricted retroflexion of neck, pathological deformities of spine and pelvis (Figure 1B), severe atrophy of left lower limb muscle (Figure 1C), moderate pitting edema below navel and edema of bulbar conjunctiva. She presented without any records of prenatal examinations. Maternal blood pressure (BP) was $200 / 140 \mathrm{~mm} \mathrm{Hg}$, heart rate was 123 beats per min, respiratory rate was 22 breaths per minute, and arterial blood oxygen saturation $\left(\mathrm{SaO}_{2}\right)$ was $99 \%$. Her breathing sounds on both sides were rough and crackles were heard at base of both lungs. Fetal heart rate (FHR) fluctuated between 110 and 140 beats per minute. The results of laboratory tests are presented in Table 1. Non-invasive cardiac function examination revealed a low output and highresistance status. A 12-lead electrocardiogram (ECG) showed nodal tachycardia; biphasic, inversion or flat T-wave in leads

Table 1 Laboratory data at patient presentation and follow-up.*

\begin{tabular}{|c|c|c|c|c|c|c|c|}
\hline \multirow[b]{2}{*}{ Variable } & \multicolumn{7}{|c|}{ Follow-up } \\
\hline & Presentation & $1 \mathrm{hr}$ Pre-op & 9 hr Post-op & 1 d Post-op & 2 d Post-op & 5 d Post-op & Normal Range \\
\hline Erythrocyte count $\left(\times 10^{12} \cdot \mathrm{L}^{-1}\right)$ & 4.97 & 3.44 & 2.49 & 3.08 & 3.50 & 3.42 & $3.50-5.50$ \\
\hline Hemoglobin (g. $\mathrm{L}^{-1}$ ) & 141.0 & 104.0 & 84.0 & 91.0 & 104.0 & 105.0 & $110.0-150.0$ \\
\hline Hematocrit (\%) & 0.47 & 0.33 & 0.22 & 0.29 & 0.34 & 0.31 & $0.30-0.50$ \\
\hline White-cell count $\left(\times 10^{9} \cdot L^{-1}\right)$ & 8.7 & 5.4 & 6.4 & 9.4 & 6.9 & 5.9 & $4.0-10.0$ \\
\hline Platelet count $\left(\times 10^{9} \cdot \mathrm{L}^{-1}\right)$ & 80.0 & 54.0 & 67.0 & 83.0 & 90.0 & 99.0 & $100.0-300.0$ \\
\hline $\begin{array}{l}\text { Aspartate aminotransferase } \\
\left(\text { IU. } L^{-1}\right)\end{array}$ & 175 & 152 & 114 & 166 & 119 & 28 & $0-45$ \\
\hline $\begin{array}{l}\text { Alanine aminotransferase } \\
\left(\mathrm{IU} . \mathrm{L}^{-1}\right)\end{array}$ & 197 & 183 & 140 & 176 & 172 & 65 & $0-45$ \\
\hline Total bilirubin $\left(\mu \mathrm{M} \cdot \mathrm{L}^{-1}\right)$ & 26.2 & 11.1 & 15.6 & 17.1 & 13.5 & & $3-22$ \\
\hline $\begin{array}{l}\text { Alkaline phosphatase } \\
\left(\mathrm{IU} . \mathrm{L}^{-1}\right)\end{array}$ & 315 & 264 & 209 & 188 & 190 & & $15-150$ \\
\hline $\begin{array}{l}\text { Lactate dehydrogenase } \\
\left(\text { IU. } L^{-1}\right)\end{array}$ & 694 & 536 & 518 & 574 & 358 & & $110-250$ \\
\hline Urine protein & +++ & +++ & +++ & +++ & ++ & ++ & - \\
\hline Urine occult blood & + & ++ & ++ & + & + & \pm & - \\
\hline Creatinine $\left(\mu M \cdot L^{-1}\right)$ & 165.7 & 175.2 & 164.3 & 175.9 & 159.6 & 146.8 & $36-123$ \\
\hline Urea nitrogen $\left(m M \cdot L^{-1}\right)$ & 11.95 & 11.09 & 10.19 & 8.24 & 4.86 & 6.201 & $2.1-7.2$ \\
\hline
\end{tabular}

* The normal ranges of the variables are based on the Chinese population. To convert the values for urea nitrogen to milligram per deciliter, multiply by 2.801 . To convert the values for creatinine to milligram per deciliter, multiply by 0.011 . To convert the values for total bilirubin to milligram per deciliter, multiply by 0.058 . Op: operation. 


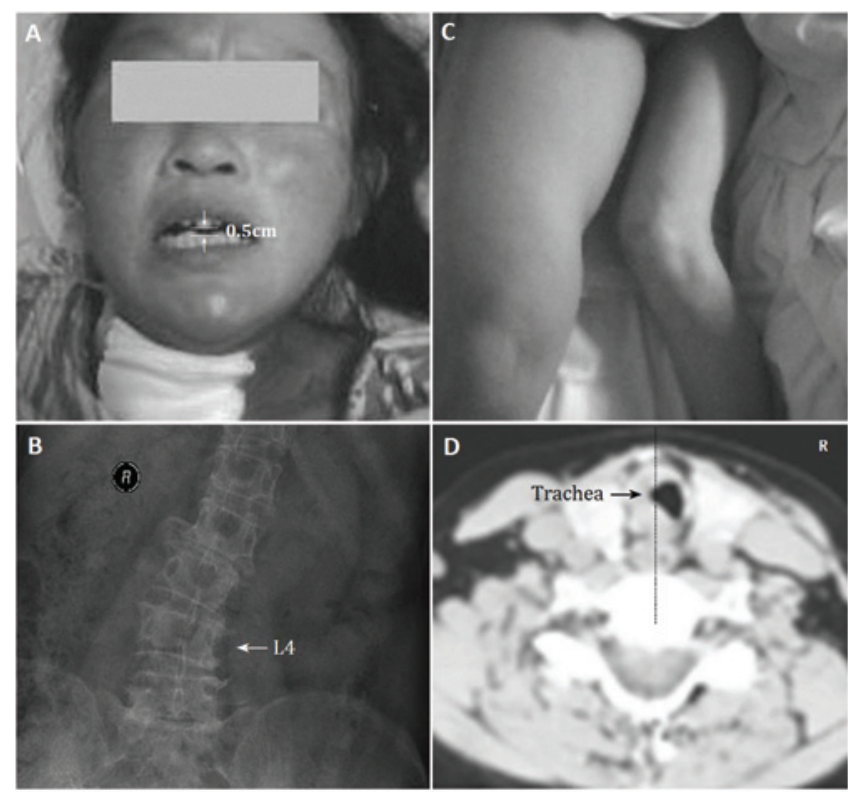

Figure 1 Patient's overall condition.

DII, DIII, aVF and V4 to V6; and high QRS wave in precordial leads (Figure 2 ). We performed an echography examination and found a hematoma with $5.3 \times 4.7 \times 2.6 \mathrm{~cm}^{3}$ between the separation of placenta and uterus. Finally, we reached the diagnosis of severe preeclampsia with HELLP syndrome, possible placental abruption, MODS, scarred uterus, spinal deformity, inclinatio pelvis, and upper airway displacement. Therefore, hydralazine was prescribed, starting with a dosage of $10 \mathrm{mg}$ four times daily for the first 2 days, and increasing to $25 \mathrm{mg}$ four times daily for the following 2 days. The BP fluctuated between 190-210/135-140 mm Hg after hydralazine treatment. At 9 A.M. on day 5, fetal distress appeared and after clinical discussion expert obstetricians decided upon urgent cesarean section. Prior to surgery, they prescribed intravenous phentolamine $5 \mathrm{mg}$ and magnesium sulphate $1 \mathrm{~g}$ in $25 \%$ solution, and intramuscular betamethasone $0.1 \mathrm{mg}$ for preparing the cesarean section. Blood pressure was monitored continuously, being persistently maintained between 180-190/130-140 mm Hg.

\section{Anaesthesia Management}

We received informed consent before anesthesia. Given the deformed lumbar spine and a history of spinal surgery combined with a coagulation problem (laboratory tests were presented in Table 2), we chose general anesthesia. Given the movement-limited mandible and cervical spine, we first attempted oral tracheal intubation but failed. Next, we tried a blind nasotracheal intubation using an endotracheal tube (inner diameter, ID $5.0 \mathrm{~mm}$ ) under analgesia with remifentanil $10 \mu \mathrm{g}$ i.v. and sedation with propofol $30 \mathrm{mg}$ i.v., plus

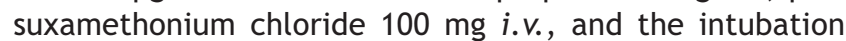
succeeded. After tracheal intubation, the patient's BP was $220 / 130 \mathrm{~mm} \mathrm{Hg}$. Then, labetalol $100 \mathrm{mg}$ i.v. was given. Subsequently, cesarean section was performed under general anesthesia with intravenous injection of propofol $120 \mathrm{mg}$ and suxamethonium chloride $100 \mathrm{mg}$ combined with local infiltration anesthesia. Two minutes later, a live male infant with 1-minute Apgar score of 2 and weight of 1,400 g was delivered. The 5-minute Apgar score was 5, and the umbilical cord arterial $\mathrm{pH}=7.19$. The newborn was transferred into the pediatric unit for further care and resuscitation. During surgery, the obstetricians confirmed the diagnosis of placental abruption. After the baby was delivered, they gave an immediate supplemental injection of fentanyl $0.1 \mathrm{mg}$, vecuronium $4 \mathrm{mg}$ and infused additional remifentanil $0.25 \mu \mathrm{g} \cdot \mathrm{kg}^{-1} \cdot \mathrm{min}^{-1}$ and propofol $150 \mu \mathrm{g} \cdot \mathrm{kg}^{-1}$. $\mathrm{min}^{-1}$ continuously for maintenance. Intraoperative monitoring variables included three-lead electrocardiography (80-120 beats per min), invasive systolic and diastolic BP (140-160/90-100 mm Hg), central venous pressure (CVP 6-9 $\mathrm{cm} \mathrm{H}_{2} \mathrm{O}$ ), fingertip pulse oximetry (97$100 \%)$, and pressure of end-tidal carbon dioxide $\left(\mathrm{P}_{\mathrm{ET}} \mathrm{CO}_{2}, 33\right.$ $40 \mathrm{~mm} \mathrm{Hg}$ ). The total transfusion included lactated Ringer's solution $500 \mathrm{~mL}$, platelet suspension $600 \mathrm{~mL}$, fresh frozen plasma $440 \mathrm{~mL}$, plasma cryoprecipitate $6 \mathrm{IU}(120 \mathrm{~mL})$. The total fluid output was $900 \mathrm{ml}$ including intraoperative blood loss $550 \mathrm{~mL}$ and urine $350 \mathrm{~mL}$. Surgery lasted 35 minutes. Neuromuscular blockade was not reversed pharmacologically

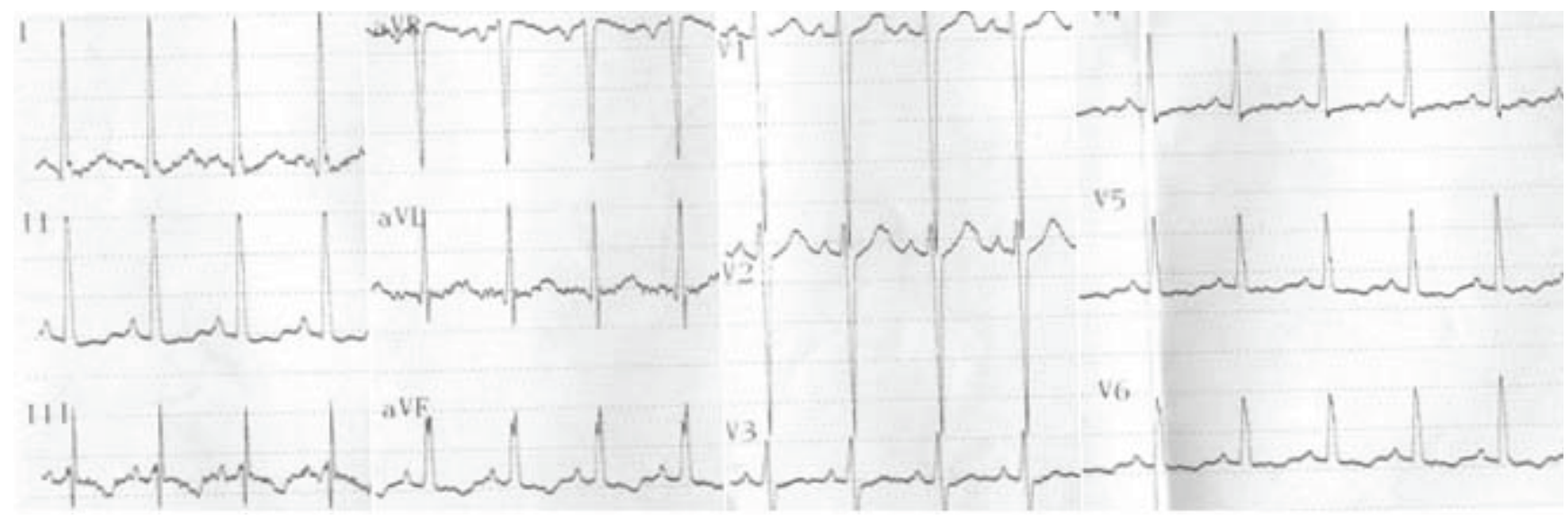

Figure 2 Patient's 12-lead electrocardiography at presentation. 
Table 2 Laboratory tests for coagulation screening.*

\begin{tabular}{|c|c|c|c|c|c|}
\hline \multirow[b]{2}{*}{ Variable } & \multicolumn{5}{|c|}{ Follow-up } \\
\hline & Presentation & 4 d Pre-op & 2 d Pre-op & $1 \mathrm{~h}$ Prior Anesthesia & Normal Range \\
\hline Prothrombin time $(\mathrm{sec})$ & 24 & 22 & 24 & 27 & $12-18$ \\
\hline $\begin{array}{l}\text { Activated partial thromboplastin } \\
\text { time (sec) }\end{array}$ & 66 & 53 & 63 & 65 & $30-54$ \\
\hline Thrombin time (sec) & 19 & 14 & 16 & 20 & $12-16$ \\
\hline Fibrinogen (g. $\left.\mathrm{L}^{-1}\right)$ & 1.8 & 1.8 & 1.7 & 1.5 & $2.0-4.0$ \\
\hline
\end{tabular}

and the patient resumed spontaneous respiration and was extubated according to the standard train-of-four (TOF) and clinical criteria.

After successful extubation, the patient was transferred into postoperative maternal intensive care unit (ICU) for further observation. In ICU, the patient's BP maintained around 200/100 $\mathrm{mm} \mathrm{Hg}$, CVP was around $10 \mathrm{~cm} \mathrm{H} \mathrm{H}_{2}$, and heart rate was 85 beats per min. Labetalol $100 \mathrm{mg}$ and phentolamine $5 \mathrm{mg}$ were prescribed for controlling hypertension. Additional nitroglycerin 5-10 $\mu \mathrm{g}$. min $^{-1}$ was infused continuously after volume expansion with lactated Ringer's solution $10 \mathrm{~mL} \cdot \mathrm{kg}^{-1}$, but the BP still fluctuated at high levels. So we replaced nitroglycerin for sodium nitroprusside $0.5-1.0 \mu \mathrm{gg}^{-1} \mathrm{~min}^{-1}$; however, it still played no role (BP 205/100 mm Hg). The patient suddenly displayed agitation, and midazolam $3 \mathrm{mg}$ i.v. was injected. Later, she calmed down and her BP decreased and fluctuated between 140-175/75-95 mm Hg. On the following day, her heart rate was $70-80$ beats per min, and her liver and kidney functions gradually recovered with the exception of creatinine $146.8 \mu \mathrm{M} . \mathrm{L}^{-1}$, alanine aminotransferase $65 \mathrm{IU} . \mathrm{L}^{-1}$ and mild urine protein. On the seventh postoperative day, the patient was discharged directly home from the ICU. One month later, a computerized tomography (CT) scan was performed to assess the patient's airway condition and found nothing but cervical trachea shifted to the right (Figure 1D).

\section{Discussion}

The decision of anesthesia for preeclamptic patients mainly depends upon an overall assessment of the benefits and harms concerning the effect of anesthesia on mothers and babies. When preeclampsia manifested with HELLP syndrome, coagulopathy and severe multi-organ dysfunction and cesarean delivery is decided, general anesthesia might be a safer method over neuraxial blockade, as long as the airway is successfully managed. Although our patient safely experienced the whole process of anesthesia and surgery, there were shortcomings in our management of this case. This calls for further discussion on these points concerning how to make a clinical decision when faced with such a patient.

HELLP syndrome is characterized by microangiopathic hemolytic anemia, elevation of liver enzymes resulting from intravascular disposition of fibrin in the hepatic sinusoids, and decreased circulating platelets secondary to the increased rate of consumption ${ }^{10}$. It is now regarded as a metamorphosis of severe preeclampsia or a complication occurring in 5-10 per thousand pregnancies and in $10-20 \%$ of cases with severe preeclampsia ${ }^{11-18}$, which poses high risk to maternal and fetal morbidity or mortality as well as long-term depression and chronic hypertension ${ }^{10-21}$. Our patient was diagnosed with class 1 in the Tennessee Classification System (platelets $\leq$ $100 \times 10^{9} . \mathrm{L}^{-1}, \mathrm{AST} \geq 70 \mathrm{IU} . \mathrm{L}^{-1}, \mathrm{LDH} \geq 600 \mathrm{IU} . \mathrm{L}^{-1}$, serum bilirubin $\left.\geq 20.5 \mu \mathrm{M} . \mathrm{L}^{-1}\right)^{13,18}$ and class 2 in the Mississippi-Triple Class System (platelets $\leq 100 \times 10^{9} . \mathrm{L}^{-1} \geq 50 \times 10^{9} . \mathrm{L}^{-1}$, AST or ALT $\geq 70$ IU. $\left.\mathrm{L}^{-1}, \mathrm{LDH} \geq 600 \mathrm{IU} . \mathrm{L}^{-1}\right)^{12}$. In general, conservative treatments are recommended to these patients for controlling BP to the safety level and for promoting the overall situations of the patients to better. However, when the patient condition worsens, cesarean section should be performed to cease pregnancy to eliminate the progressive threat on mothers and babies, ${ }^{22}$ and neuraxial blockade is preferred as the first line selection over general anesthesia when thrombocytopenia is moderate, though not progressive ${ }^{5,6}$. In our patient, however, the deformed spine plus a history of spinal surgery and progressive coagulopathy made neuraxial anesthesia pose high risks on the mother. Therefore, general anesthesia was carried out after critical discussion among expert anesthesiologists and obstetricians.

Difficult airway is one of the major concerns when general anesthesia was given for cesarean section because of the following two reasons: first, pregnancy-induced fibroelastic edema results in a significant reduction in the space of oral and cavum larynges 9 ; second, movement limitation of cervical spine results from pregnancy obesity ${ }^{23}$. These factors lead to an increase in the incidence of Mallampati classes 3 and $4{ }^{9}$. In addition to these factors, our patient had a severely limited mouth opening and displaced upper trachea that undoubtedly increases the difficulty of airway management during general anesthesia. Despite our luck in succeeding in our attempt to perform a blind nasal tracheal intubation, such an attempt poses a risk of increasing posterior airway management troubles in the case of failure, since repeated blind attempts would injure the mucous membrane of the laryngeal part of pharynx, which would finally result in dominant edema, or even a possibly uncontrolled bleeding due to the dysfunction of coagulation. This is the major shortcoming of our airway management. As recommended by the SIAARTI study group, a fiberoptic intubation may be the first choice for predictable ventilation difficulty under anesthesia if cooperation or awake if no cooperation ${ }^{24}$. The oral route of fiberoptic intubation in our patient was restricted because of the limited opening size of her mouth, so a nasal fiberoptic intubation might be the best choice. In addition, if the fiberoptic intubation failed, the last choice 
might be the invasive airway access such as tracheostomy, performed by trained staff as suggested by the difficult airway management Task Force from the American Society of Anesthesiologists ${ }^{25}$. From this guideline, other methods such as bronchofiberscope-guided or blind nasal or retrograde intubation could be selected if the oral pathway was limited. However, if the patient had a severe coagulopathy, the blind nasal intubation should be avoided because such practice might increase the risk of bleeding and aspiration, and if the first attempt failed, repeated attempts would undoubtedly prolong the time of intubation that would finally decrease the success rate of saving the life of the mother and the baby. At the same time, blind nasal intubation would increase the failure rate of alternative methods that follow.

We inserted an arterial line for monitoring blood pressure continuously and providing repeated blood samplings, and a central venous tube for measuring intravascular volume. While such invasive monitors are not routine procedures in preeclamptic patients, it is necessary in such a case. Direct assessment of the central hemodynamics is a necessary step for obstetric patients undergoing general anesthesia. Plasma exchange is suggested for refractory HELLP syndrome ${ }^{26}$. Our case and other successful administration of fresh frozen plasma ${ }^{27}$ make it a useful regimen for this type of patient.

In summary, the question of how to realize the optimal therapy weighing the benefits and risks is based mainly on an overall understanding and comprehensive assessment of the patient's pathophysiological conditions. With our patient, a post hoc critical appraisal of clinical decisions on patient management was made to learn lessons when the best practice (the safer and more effective treatment) was not performed. Therefore, we learned that adequate preoperative preparation is the prerequisite of successful clinical practice. For patients with preeclampsia, as reported by Galloway ${ }^{28}$, it is essential to be aware of the following: (1) effective and safe perioperative management requires a multidisciplinary approach, and a fast and good communication between specialist clinicians involved in the process of decision making is necessary; (2) neuraxial block, especially spinal anesthesia, is the first choice for Caesarean section if only a moderate but not progressive thrombocytopenia exists; (3) general anesthesia with adequate sedation and analgesia is needed to control the stress response to intubation well, especially in severe hypertensive patients with neurological signs, or to prevent major cerebral complications; (4) invasive techniques such as tracheotomy, artery and deep-vein catheterizations should be considered; (5) rapid sequence induction of general anesthesia should be used for emergency full-stomach patient if contraindications exist for neuraxial anesthesia after an accurate analysis of the benefits and harms; (6) there should be extended awareness towards the potential risk of difficult airway; (7) predictable ventilation difficulty should be treated following guidelines ${ }^{24,25} ;(8)$ invasive monitoring and standby mechanical ventilation are supportive maneuvers for successful anesthetic management; (9) postpartum plasma exchange is an effective therapeutic method for preeclamptic patients manifested with HELLP syndrome or/and marked coagulopathy.

\section{Acknowledgements}

Authors obtained written consent from the patient for publishing this case report and accompanying photos. The authors appreciate the patient's consent to publish this report. This work has been supported in part by the Development Grant of Medical Science and Technology of Nanjing Medical University (09NJMUZ39) and Nanjing Municipal Outstanding Young Scientist in Medical Development (201208009). We thank all obstetricians, pediatricians, nurses, anesthesiologists and radiologists who participated in diagnosing and treating the patient in our hospital.

\section{References}

1. Poole $\mathrm{JH}$ - Multiorgan dysfunction in the perinatal patient. Crit Care Nurs Clin North Am. 2004;16:193-204.

2. Sibai B, Dekker G, Kupferminc M - Pre-eclampsia. Lancet. 2005;365:785-799.

3. Sibai BM, Stella CL - Diagnosis and management of atypical preeclampsia-eclampsia. Am J Obstet Gynecol. 2009;200:481. e1-e7.

4. Koyama S, Tomimatsu T, Kanagawa T et al. - Spinal subarachnoid hematoma following spinal anesthesia in a patient with HELLP syndrome. Int J Obstet Anesth. 2010;19:87-91.

5. Crosby ET, Preston R - Obstetrical anaesthesia for a parturient with preeclampsia, HELLP syndrome and acute cortical blindness. Can J Anaesth. 1998;45:452-459.

6. Okafor UV, Efetie ER, Igwe W, Okezie O - Anaesthetic management of patients with preeclampsia/eclampsia and perinatal outcome. J Matern Fetal Neonatal Med. 2009;22:688-692.

7. Gogarten W - Preeclampsia and anaesthesia. Curr Opin Anaesthesiol. 2009;22:347-351.

8. Richa F, Yazigi A, Nasser E, Dagher C, Antakly MC - General anesthesia with remifentanil for Cesarean section in a patient with HELLP syndrome. Acta Anaesthesiol Scand. 2005;49:418420.

9. Boutonnet M, Faitot V, Katz A, Salomon L, Keita H - Mallampati class changes during pregnancy, labour, and after delivery: can these be predicted? Br J Anaesth. 2010;104:67-70.

10. Joshi D, James A, Quaglia A, Westbrook RH, Heneghan MA - Liver disease in pregnancy. Lancet. 2010;375:594-605.

11. Marik PE - Hypertensive disorders of pregnancy. Postgrad Med. 2009;121:69-76.

12. Martin JN Jr, Rose $\mathrm{CH}$, Briery $\mathrm{CM}$ - Understanding and managing HELLP syndrome: the integral role of aggressive glucocorticoids for mother and child. Am J Obstet Gynecol. 2006;195:914934.

13. Sibai BM - Diagnosis, controversies, and management of the syndrome of hemolysis, elevated liver enzymes, and low platelet count. Obstet Gynecol. 2004;103:981-991.

14. Celik C, Gezginc K, Altintepe Let al. - Results of the pregnancies with HELLP syndrome. Ren Fail. 2003;25:613-618.

15. Ertan AK, Wagner S, Hendrik HJ, Tanriverdi HA, Schmidt W Clinical and biophysical aspects of HELLP-syndrome. J Perinat Med. 2002;30:483-489.

16. Magann EF, Martin JN Jr - Twelve steps to optimal management of HELLP syndrome. Clin Obstet Gynecol. 1999;42:532-550.

17. Audibert F, Friedman SA, Frangieh AY, Sibai BM - Clinical utility of strict diagnostic criteria for the HELLP (hemolysis, elevated liver enzymes, and low platelets) syndrome. Am J Obstet Gynecol. 1996;175:460-464.

18. Sibai BM - The HELLP syndrome (hemolysis, elevated liver enzymes, and low platelets): much ado about nothing? Am J Obstet Gynecol. 1990;162:311-316. 
19. Habli M, Eftekhari N, Wiebracht E, Bombrys A, Khabbaz M, How $H$, Sibai B - Long-term maternal and subsequent pregnancy outcomes 5 years after hemolysis, elevated liver enzymes, and low platelets (HELLP) syndrome. Am J Obstet Gynecol. 2009;201:385.e1-e5.

20. Pokharel SM, Chattopadhyay SK, Jaiswal R, Shakya P - HELLP syndrome-a pregnancy disorder with poor prognosis. Nepal Med Coll J. 2008;10:260-263.

21. Vigil-De Gracia P - Maternal deaths due to eclampsia and HELLP syndrome. Int J Gynaecol Obstet. 2009;104:90-94.

22. Levy DM - Emergency Caesarean section: best practice. Anaesthesia. 2006;61:786-791.

23. Davies GA, Maxwell C, McLeod L et al. - Obesity in pregnancy. J Obstet Gynaecol Can. 2010;32:165-173.

24. Petrini F, Accorsi A, Adrario E et al. - Recommendations for airway control and difficult airway management. Minerva Anestesiol. 2005;71:617-657.
25. American Society of Anesthesiologists Task Force on Management of the Difficult Airway: Practice guidelines for management of the difficult airway - An updated report by the American Society of Anesthesiologists Task Force on Management of the Difficult Airway. Anesthesiology. 2003;98:1269-1277.

26. Martin JN Jr, Files JC, Blake PG, Perry KG Jr, Morrison JC, Norman $\mathrm{PH}$ - Postpartum plasma exchange for atypical preeclampsiaeclampsia as HELLP (hemolysis, elevated liver enzymes, and low platelets) syndrome. Am J Obstet Gynecol. 1995;172:11071127.

27. Martin JN Jr, Perry KG Jr, Roberts WE et al. Plasma exchange for preeclampsia: III. Immediate peripartal utilization for selected patients with HELLP syndrome. J Clin Apher. 1994;9:162-165.

28. Galloway S, Lyons G - Preeclampsia complicated by placental abruption, HELLP, coagulopathy and renal failure-further lessons. Int J Obstet Anesth. 2003;12:35-39. 